\title{
A family and population study of the genetic polymorphism of debrisoquine oxidation in a white British population
}

\author{
D A PRICE EVANS, A MAHGOUB, T P SLOAN, J R IDLE, \\ AND R L SMITH
}

From the Department of Medicine, University of Liverpool, PO Box 147, Liverpool L69 3BX; and the Department of Biochemical and Experimental Pharmacology, St Mary's Hospital Medical School, Paddington, London W2 1PG.

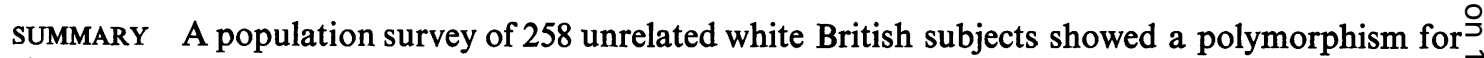
the 4-oxidation of debrisoquine. 'Extensive metabolisers' (EM) and 'poor metabolisers' (PM) are recognisable, $8.9 \%$ of the population being PM. Nine pedigrees ascertained through PM probands show that the PM phenotype is an autosomal Mendelian recessive character. The EM phenotype is $\vec{\bullet}$ dominant and the degree of dominance has been estimated at 30\%. PM subjects are more prone to\% hypotension during debrisoquine therapy. The alleles controlling this polymorphism appear to ${ }^{\circ}$ control the oxidation of other drugs.

The antihypertensive drug, debrisoquine, undergoes metabolic hydroxylation in man. The formation of the major metabolite, namely 4-hydroxydebrisoquine, displays polymorphism in the population. ${ }^{1}$ In this study, two well-resolved phenotypes were seen. The first was characterised by persons who 4-hydroxylated the majority of the drug and were thus designated extensive metabolisers (EM phenotype, about $95 \%$ of the white British population). For these subjects, the metabolic ratio (MR), defined as $\%$ of dose as debrisoquine $\%$ of dose as 4-hydroxy-debrisoquine excreted in the 0 to 8 hour urine, was of the range 0.01 to 9 . In the second phenotype (poor metabolisers, PM, about $5 \%$ of British whites), MR values greater than 20 were observed, and thus these subjects had a relative inability to carry out debrisoquine 4-hydroxylation. The few families studied suggested strongly that PM subjects were autosomal recessives.

In this paper, we describe a more extensive population study of white British subjects, together with further family data which uphold the resolution of the population into EM and PM phenotypes and confirm that the PM phenotype is an autosomal recessive trait.

Received for publication 6 June 1979

\section{Methods}

VOLUNTEER SUBJECTS

Subjects were studied in both London and Liverpool. The volunteers comprised 97 healthy staff ando students from the University of Liverpool Medical School and 161 from St Mary's Hospital Medicalక School, part of whom were studied by Mahgoub et al..$^{{ }^{\circ}}$

\section{FAMILY MEMBERS}

The probands for the family studies were the poor metabolisers identified in the London and Liverpool population studies.

\section{PHENOTYPING PROCEDURE}

As described by Mahgoub et al, ${ }^{1}$ a single $10 \mathrm{mgN}$ Declinax tablet (Roche) (equivalent to $12.8 \mathrm{mg}$ debrisoquine sulphate) was ingested in the fasting state by volunteer subjects who had not beencw exposed to any recent drug medication. The bladder was emptied before dosing and thereafter all urineo was collected up to 8 hours. Urine volume wast recorded and an aliquot stored at $-20^{\circ} \mathrm{C}$ to await ${ }^{\circ}$ analysis.

ANALYTICAL PROCEDURE

Urine was analysed for debrisoquine and $4-\frac{\rho}{\mathrm{D}}$ hydroxy-debrisoquine by electron-capture gas-chro- $\frac{0}{\sigma}$ 
matography after derivatisation with hexafluoroacetylacetone as described by Idle $e t$ al. ${ }^{2}$ From these data the metabolic ratio (MR) was calculated from the expression:

$$
\left\{\frac{\% \text { of dose as debrisoquine }}{\% \text { of dose as 4-hydroxy-debrisoquine) }}\right\}
$$

excreted in the 0 to 8 hour urine. The transformation $\log _{10}$ MR was distributed in an approximately normal manner and was used for computation.

\section{Results}

The variable log MR was found to be reproducible in eight EM and nine PM subjects on whom complete repeat tests were performed on two separate occasions. Fig 1 shows a scattergram of the first estimate of $\log$ MR plotted against the second estimate of $\log$ MR. The non-parametric Spearman rank correlation gives $r_{s}=0.88, p<0.001$.

There was no association of either phenotype with age or sex. The urinary volumes of both phenotypes were within the same range and MR was not dependent on urine volume within either phenotype. There was no heterogeneity in MR values between the London and the Liverpool samples. The distribution of $\log \mathrm{MR}$ in 258 unrelated white British subjects is shown in fig 2 . Two phenotypes are apparent in the population with an antimode of 1.10. Poor metabolisers are thus defined as subjects with $\log$ MR $>1 \cdot 10$. Twenty-three phenotypically poor metabolisers were identified, 8 of 97 subjects tested in Liverpool and 15 of 161 subjects tested in London. The PM phenotype frequency in the total sample was thus $0 \cdot 0891$, approximately twice that found by Mahgoub et al $^{1}$ in a smaller sample.

Families of the probands derived from among the 23 PM subjects in fig 2 were phenotyped as described for the unrelated volunteers and the results are shown in the table. Metabolic ratios greater than $12.6(\log M R>1 \cdot 10)$ are indicative of poor meta-

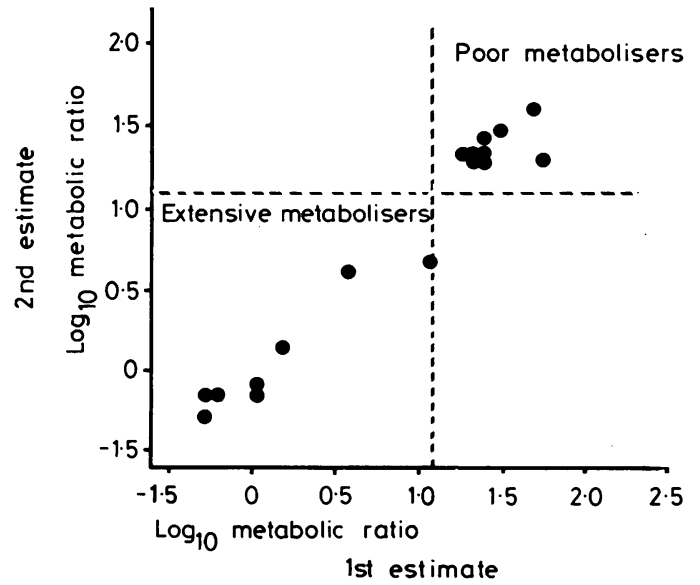

FIG 1 Repeat phenotyping tests carried out on separate occasions in unrelated people of both phenotypes

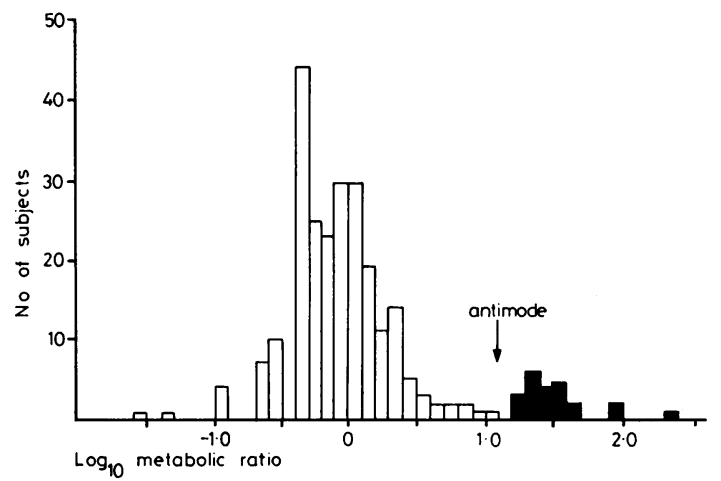

FIG 2 Frequency distribution of $\log _{10}$ metabolic ratio in 258 unrelated white British subjects

bolisers. In pedigrees 1 to 5, all PM offspring had a PM parent (either sex), but for pedigrees 6 to 9 , both parents of PM offspring were extensive metabolisers (EM). This clearly shows that PM is an

TABLE Log 10 urinary metabolic ratios in 9 pedigrees ascertained through probands who are poor metabolisers

\begin{tabular}{|c|c|c|c|c|c|c|c|}
\hline \multirow[t]{2}{*}{ Pedigree no } & \multicolumn{2}{|l|}{ Parents } & \multicolumn{5}{|l|}{ Offspring } \\
\hline & Father & Mother & 1 & 2 & 3 & 4 & 5 \\
\hline 3 & T.48 & $\rightarrow 1 \cdot 52$ & $0.15 \mathrm{M}$ & $0.18 \mathrm{M}$ & $\underline{0} .42 \mathrm{M}$ & $0.11 \mathrm{M}$ & $0.15 \mathrm{M}$ \\
\hline$\because$ & $\rightarrow 1 \cdot 29$ & $\overline{1} \cdot 78$ & $\overline{1} \cdot 78 \mathrm{M}$ & $0.58 \mathrm{M}$ & $1.95 \mathrm{M}$ & - & - \\
\hline 3 & $1 \cdot 32$ & 0.23 & $1.43 \mathrm{M}$ & $\rightarrow 1.33 \mathrm{M}$ & $0.40 \mathrm{M}$ & - & - \\
\hline 4 & 1.40 & Not available & $\rightarrow 1 \cdot 32$ & 1.90 & - & - & - \\
\hline 5 & $2 \cdot 29$ & 0.04 & $\rightarrow 1.48 \mathrm{M}$ & $1.88 \mathrm{M}$ & - & - & - \\
\hline 6 & 0.28 & 0.48 & $\rightarrow 1.41$ & $1 \cdot 32 \mathrm{M}$ & $0.32 \mathrm{M}$ & $1.84 \mathrm{M}$ & - \\
\hline 7 & 0.48 & 0.34 & $\rightarrow 1 \cdot 59$ & $1 \cdot 26$ & — & - & - \\
\hline 8 & 0.63 & 1.00 & $\rightarrow 1.30 \mathrm{M}$ & - & - & - & - \\
\hline 9 & 0.72 & 0.04 & $\rightarrow 1 \cdot 32 \mathrm{M}$ & $0.77 \mathrm{M}$ & $0.64 \mathrm{M}$ & 一 & - \\
\hline
\end{tabular}

$\rightarrow$ proband; $M$ indicates male offspring. 
autosomal recessive character. An estimate can, therefore, be made of the frequency of the allele controlling poor metabolism $\left(0 \cdot 2986 \pm \mathrm{SE} \mathrm{0.0297)^{3 }}\right.$ and the allele controlling extensive metabolism $(0 \cdot 7014)$. Thus, the expected genotype frequencies are homozygous PM 0.0891, heterozygous EM $0 \cdot 4189$, and homozygous EM $0 \cdot 4920$.

An estimate of the degree of dominance can be made from the extent of displacement of the mean observed log MR value for heterozygotes (positively identified from family pedigrees) from the mid-point between the mean log MR values for the two homozygous states. From the data given in the table and from Mahgoub et al, ${ }^{1}$ it is possible to recognise 21 heterozygotes who have a mean value of $0.27 \pm 0.31(\log \mathrm{MR} \pm \mathrm{SD})$. Accordingly, the mean value $(x)$ for homozygous dominants can be calculated from the expected number of homozygous (127) and heterozygous (108) subjects who comprise the extensive metabolisers (235) in fig 2 as follows:

$$
\begin{array}{lll}
\begin{array}{l}
\text { Sum of values } \\
\text { for } 235 \text { extensive } \\
\text { metabolisers }
\end{array} & \begin{array}{l}
\text { Sum of values } 127 \\
\text { homozygotes }
\end{array} & \begin{array}{c}
\text { Sum of values } \\
\text { for } 108 \\
\text { heterozygotes }
\end{array} \\
-22.58 & =127 \times & +108 \times 0.27
\end{array}
$$

The estimated mean value $(x)$ for homozygous dominants is therefore $\overline{1} \cdot 5926$ (mean MR $=0 \cdot 39$ ). The observed mean value for the homozygous recessives ( 23 in fig 2 plus the eight non-probands in the table plus an additional one from the extended family B of Mahgoub et al, ${ }^{1}$ making 32 in all) is $1 \cdot 53$ (mean MR $=33.9$ ). The mid-point between the two homozygous means is thus estimated as $0 \cdot 56$. So the displacement of the observed heterozygous value from the expected mid-point value (expected for zero dominance) is $0 \cdot 29$, which gives an approximate dominance of $30 \%$.

\section{Discussion}

Two debrisoquine oxidation phenotypes were characterised, first a Mendelian autosomal recessive character (PM phenotype $=\mathbf{8 . 9} \%$ of population) with metabolic ratios greater than $12.8(\log$ MR $>1 \cdot 10$ ), and secondly a dominant character (EM phenotype $91.2 \%$ ) comprising both homozygous dominants and heterozygotes in whom a strong (about $30 \%$ ) dominance effect is observed.

The calculation of dominance gives a clearer picture of the genetic structure of the white British population. There is a practical significance to this finding because if the homozygous EM genotype and the heterozygote had the same distribution they would probably be at equal risk of adverse reactions.

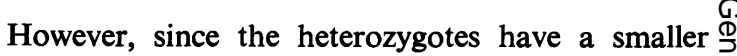
metabolic capacity than the homozygotes it is $\stackrel{\mathbb{P}}{?}$ probable that they are more prone to adverse effects of drugs undergoing C-oxidation.

The biochemical basis of the debrisoquine? polymorphism is unknown, but it is possibly $\frac{\overline{\bar{O}}}{\overline{\mathrm{n}}}$ concerned with a hepatic mono-oxygenase enzyme $\stackrel{\sim}{\circ}$ which may or may not involve the haemoprotein $\AA$ cytochrome P450 which is considered central to the processes of drug oxidation. As encountered with most $\vec{\circ}$ polymorphisms of drug metabolism, the natural or endogenous substrate(s) remains unknown. The $\vec{\omega}$ clinical importance of the debrisoquine polymor- $\stackrel{S}{S}$ phism has been stressed by Sloan et $a l^{4}$ and is $\overrightarrow{3}$ reiterated here. The oxidative metabolism of other drugs appears to be under the control of the same $\vec{N}$ alleles as debrisoquine hydroxylation. These drugs include guanoxan and phenacetin, ${ }^{4}$ phenytoin, ${ }^{5} \vec{N}$ metiamide, ${ }^{6}$ and 4-methoxyamphetamine ${ }^{7}$; other $\circ$ drugs may be added to this list with the passage of $\rightarrow$ time. In addition, hypotension is produced by a $\rightarrow$ standard $20 \mathrm{mg}$ therapeutic dose of debrisoquine in poor metabolisers, but not in extensive metabolisers. ${ }^{8} \overrightarrow{\vec{\theta}}$ It would appear, therefore, that the alleles controlling $\mathscr{\infty}$ debrisoquine metabolism, and the resulting pheno-. type of a subject, are of considerable medical importance.

We gratefully acknowledge the invaluable assistance $\frac{\varrho}{\circ}$ of Mrs A Howard Jones SRN, Nuffield Unit of $\propto$ Medical Genetics, Department of Medicine, $\overrightarrow{\vec{O}}$ University of Liverpool, for carrying out tests on 3 probands and family members. AM was supported by the Egyptian Education Bureau, and TPS is in receipt of an MRC Studentship. We thank the Wellcome Trust for a grant for interdisciplinary research. The study was dependent on the co-operation and goodwill of probands and family members and the authors thank them.

\section{References}

1 Mahgoub A, Idle JR, Dring LG, Lancaster R, Smith RL. N Polymorphic hydroxylation of debrisoquine in man.Lancet 1977;2:584-6.

2 Idle JR, Mahgoub A, Angelo MM, Dring LG, LancasterN $R$, Smith RL. The metabolism of ${ }^{14} \mathrm{C}$ debrisoquine in man. Br J Clin Pharmacol 1979;7:257-66.

3 Emery AEH. Methodology in medical genetics. Edinburgh Churchill Livingstone, 1976.

- Sloan TP, Mahgoub A, Lancaster R, Idle JR, Smith RL. Polymorphism of carbon oxidation of drugs and clinical ${ }^{+}$ implications. Br Med J 1978;2:655-7.

5 Idle JR, Sloan TP, Smith RL, Wakile LA. The application of the phenotyped panel approach to the detection of polymorphism of drug oxidation in man. Br J Pharmaco $\frac{Q}{\mathbb{D}}$ 1979;66:430-IP. 
6 Idle JR, Ritchie JC, Smith RL. Oxidation phenotype and metiamide metabolism. Br J Pharmacol 1979;66:432P.

7 Kitchen I, Tremblay J, André J, Dring LG, Idle JR, Smith RL, Williams RT. Inter-individual and inter-species variation in the metabolism of the hallucinogen 4methoxyamphetamine. Xenobiotica 1979;9:397-404.

8 Idle JR, Mahgoub A, Lancaster R, Smith RL. Hypo- tensive response to debrisoquine and hydroxylation phenotype. Life Sci 1978;22:979-84.

Requests for reprints to Professor D A Price Evans, Department of Medicine, University of Liverpool, PO Box 147, Liverpool L69 3BX. 